\title{
The European Community Household Panel: A review
}

\author{
Franco Peracchi* \\ Tor Vergata University, Faculty of Economics 00133 Rome, Italy \\ (e-mail: franco.peracchi@uniroma2.it)
}

First version received: July 2000/Final version received: October 2000

\begin{abstract}
The European Community Household Panel (ECHP) is a standardized multi-purpose annual longitudinal survey carried out at the level of the European Union. It is centrally designed and coordinated by the Statistical Office of the European Communities (Eurostat), and covers demographics, labor force behavior, income, health, education and training, housing, migration, etc.

After reviewing the organization of the survey, this paper discusses some of the issues that an applied economist potentially interested in the ECHP may face when trying to deal with these data. In particular, the paper focuses on survey attrition and nonresponse, the weighting procedures with which Eurostat tries to compensate for differential nonresponse and attrition rates, and the imputation methods adopted by Eurostat in order to deal with item nonresponse.
\end{abstract}

Key words: Panel data, nonresponse, attrition, Europanel

JEL classification: $\mathrm{C} 4, \mathrm{C} 8$

\section{Introduction}

The European Community Household Panel (ECHP) is a standardized multipurpose annual longitudinal survey carried out at the level of the European Union (EU). It is centrally designed and coordinated by the Statistical Office of the European Communities (Eurostat), and covers demographics, labor force behavior, income, health, education and training, housing, migration, etc.

\footnotetext{
* I thank an Associated Editor and seminar participants at CEMFI, ISTAT, New York University, Texas A\&M University and the University of Turin for helpful comments.
} 
The project was launched in 1992 "in response to the increasing demand in the European Union for comparable information across the Member States on income, work and employment, poverty and social exclusion, housing, health, and many other diverse social indicators concerning living conditions of private households and persons" (Eurostat 1996b).

The objective of the ECHP is to represent the population of the EU at the level of households and individuals. It aims at being both cross-sectionally and longitudinally representative, with changes in the population over time reflected by the continuous evolution of the sample - through births to sample households and the formation of new households from the split off of existing ones. This aspect differentiates the ECHP from other panels, such as the National Longitudinal Surveys in the USA, that only follow a few cohorts of individuals as they age. In this, and many other dimensions, the ECHP is patterned after the Panel Study of Income Dynamics (PSID) conducted in the USA by the Survey Research Center at the University of Michigan. ${ }^{1}$

The ECHP, initially conceived as a 3-wave panel, has now reached its 7 th wave. The first wave, conducted in 1994, included all current members of the EU except Austria, Finland and Sweden. Austria was added in the second wave conducted in 1995, Finland in the third wave conducted in 1996, and Sweden in the fourth wave conducted in 1997. Funding for 3 additional waves was approved by the European Commission in 1996 and then again in 1999. In its current form, the survey is expected to end in year 2002. At that point, it will be redesigned thoroughly or simply discontinued.

The attractive features of the ECHP for socio-economic research are its comparability across countries and over time, and the range of economic and socio-demographic information that it collects. The purpose of this paper is to discuss some of the issues that an applied economist interested in exploiting the opportunities offered by the ECHP may face when trying to deal with these data. Our discussion is based on the documents issued by Eurostat and the evidence from the publicly released data, which currently contain the first three waves of the panel.

The remainder of this paper is organized as follows. Sections 2 and 3 describe the organization of the survey (coverage, sampling design, following rules, questionnaire, fieldwork, and data editing), and data access and organization. The substantive problems of attrition and nonresponse are addressed in Sections 4-6. Specifically, Section 4 discusses the issue of nonresponse, distinguishing between unit nonresponse, item nonresponse, sample attrition, and new entry. Section 5 discusses the weighting procedures with which Eurostat tries to compensate for differential nonresponse and attrition rates. Section 6 discusses the imputation methods adopted by Eurostat in order to deal with item nonresponse. Finally, Section 7 offers some conclusions.

\footnotetext{
1 The PSID is a widely used longitudinal survey of the U.S. population. The study, designed to provide a continuous representation of individuals and the families they live in, contains detailed information on socio-economic and demographic variables. It has been ongoing since 1968. Its initial sample comprised two different components: an approximately random sample of families (the "SRC sample") and a sample of low-income families (the "SEO sample"). Data are collected annually and the publicly released micro-data files, now downloadable free of charge from the Internet (http://www.isr.umich.edu/src/psid/), contain the full span of the information collected over the course of the study. For an introduction to the PSID, see Hill (1992).
} 


\section{Organization of the survey}

The ECHP is carried out by National Data Collection Units (NDU), with Eurostat providing centralized support and coordination. The NDUs are the National Statistical Institutes in eight countries (Finland, France, Germany, Greece, Italy, Netherlands, Portugal, and Spain) and other public bodies or private organizations in the remaining countries.

The NDUs are responsible for sample selection, adaptation of the questionnaire, fieldwork, basic data processing and editing, and initial weighting of the data. Although Eurostat sets general guidelines in order to ensure comparability of survey results, the NDUs largely rely on their normal rules and routines. Unfortunately, national reporting on the survey organization is lacking, making it somewhat difficult to assess data quality.

In Belgium and the Netherlands, the ECHP was linked from the beginning to already existing national panels. In Germany, Luxembourg and the UK, instead, the first three waves of the ECHP ran parallel to existing panels with similar content, namely the German Social Economic Panel (GSOEP), the Luxembourg's Social Economic Panel (PSELL), and the British Household Panel Survey (BHPS). ${ }^{2}$ This has changed starting with the fourth (1997) wave. Partly as a consequence of the low response rates in wave 1 and the loss of sample units across waves (see Section 4 below), it was decided to merge the ECHP into the GSOEP, the PSELL and the BHPS. No evidence on the effects of this decision on data quality is available yet.

\subsection{Coverage and sampling design}

The target population of the ECHP consists of all private households throughout the national territory of each country. ${ }^{3}$ Although the same criteria are adopted to define a household, namely "sharing the same dwelling" and "common living arrangements", the precise definition is not exactly the same across countries.

All national samples are selected through probability sampling. Sampling frames and sampling procedures are not standardized across countries, however, and each NDU relies on its own methods. In most countries, the sampling frame is either the population register or a master-sample created from the latest population census. Depending on the sampling frame, we may have noncoverage of small portions of the target population, such as house-

\footnotetext{
2 The GSOEP is an annual survey of private households in Germany conducted by the German Institute of Economic Research (DIW). It has been ongoing in West Germany since 1984 (SOEP "West"). Starting in 1990, the sample has been extended to cover the territory of the former German Democratic Republic (SOEP "East"). The PSELL is an annual survey of private households in Luxembourg. It is conducted by CEPS/INSTEAD and has been ongoing since 1985 . The BHPS is an annual survey of private households in Britain (Northern Ireland excluded) conducted by the ESRC Research Center on Micro-social Change at the University of Essex. It has been ongoing since 1991. Anonymous public-use files of micro-data from these three panels are provided free of charge to college and university research centers. All three panels, as well as a number of waves of the PSID, are also included in the PAnel COmparability (PACO) database (Schaber, Schmaus \& Wagner 1993).

${ }^{3}$ Some countries exclude small parts of their national territory. For example, France excludes overseas departments and territories, Italy and the UK exclude some small islands, Spain excludes Ceuta and Melilla.
} 
holds recently arrived in a country (Ireland, Italy) or nonresidents unable to speak the national language (Greece, Netherlands).

The most common sampling procedure is two-stage sampling, with geographical areas (usually the municipalities) as primary sampling units, and households or addresses as secondary sampling units. Simple random sampling is used in Denmark, Luxembourg, Northern Ireland, and large cities in Italy and the Netherlands, whereas three-stage sampling is used in Portugal and part of France.

Originally, in 1992, Eurostat planned a minimum sample size of 1000 household per country and an enlarged sample size of 2000 households for two groups of countries: the four largest ones (Germany, France, Italy, UK) and the four economically least developed (Greece, Ireland, Portugal, Spain). The planned sample size was later expanded by a factor of four to include about 80,000 households in the initial 12 countries.

Within each household, the ECHP distinguishes between sample and nonsample persons. The definitions are the same as for the PSID. A sample person is anybody in the initial (wave 1) sample who is still alive, plus any child born after wave 1 to a sample woman. A nonsample person is any other person, not initially in the sample, who resides in a private household containing one or more sample persons. Sample and nonsample persons are eligible for personal interview if they are "adult", that is, aged 16 or older on December 31 of the year before the survey.

Table 1 shows, for each country, the size of the adult population living in private households (thousand persons aged 16+), the achieved sample size (the number of personal interviews completed) and the overall inflation factor (the ratio between the adult population and the achieved sample size) for the first three years of the ECHP. The achieved sample size is smallest for Luxembourg, which is also the smallest of the EU countries, and largest for Spain and Italy, which only rank fifth and second respectively in terms of

Table 1. Adult population living in private households (thousand persons aged 16+), achieved sample size (number of personal interviews completed) and inflation factors for the first three waves of the ECHP

\begin{tabular}{|l|rrr|rrr|rrr|}
\hline & \multicolumn{3}{|c|}{ Adult population (1000) } & \multicolumn{3}{|c|}{ Achieved sample size } & \multicolumn{3}{|c|}{ Inflation factor } \\
\cline { 2 - 11 } & 1994 & 1995 & 1996 & 1994 & 1995 & 1996 & 1994 & 1995 & 1996 \\
\hline Austria & & 6419 & 6419 & & 7437 & 7270 & & 863 & 883 \\
Belgium & 8127 & 8181 & 8200 & 6710 & 6456 & 6151 & 1211 & 1267 & 1333 \\
Denmark & 4250 & 4244 & 4283 & 5903 & 5503 & 4994 & 720 & 771 & 858 \\
Finland & & & 4021 & & & 8173 & & & 492 \\
France & 44627 & 45594 & 45871 & 14333 & 13306 & 13051 & 3114 & 3427 & 3515 \\
Germany & 67173 & 67339 & 67691 & 9490 & 9002 & 8746 & 7078 & 7480 & 7740 \\
Greece & 8465 & 8382 & 8382 & 12492 & 12271 & 11605 & 678 & 683 & 722 \\
Ireland & 2582 & 2634 & 2640 & 9904 & 8531 & 7487 & 261 & 309 & 353 \\
Italy & 46980 & 47733 & 47734 & 17729 & 17780 & 17736 & 2650 & 2685 & 2691 \\
Luxembourg & 319 & 329 & 330 & 2046 & 1968 & 1914 & 156 & 167 & 173 \\
Netherlands & 12343 & 12338 & 12155 & 9407 & 9151 & 9277 & 1312 & 1348 & 1310 \\
Portugal & 7979 & 8082 & 8029 & 11621 & 11858 & 11706 & 687 & 682 & 686 \\
Spain & 31096 & 31345 & 31610 & 17893 & 16263 & 15643 & 1738 & 1927 & 2021 \\
UK & 45387 & 46160 & 45622 & 10517 & 8386 & 6940 & 4316 & 5504 & 6574 \\
\hline
\end{tabular}


adult population. The overrepresentation of Southern European countries is unintended. It is partly a consequence of cross-country differences in response rates, and partly of German regulations on data collection that only allow a sample size of no more than 10,000 individuals. Inflation factors vary considerably across countries, from less than 500 in Finland, Ireland and Luxembourg, to over 5,000 in Germany and the UK.

\subsection{Following rules}

According to Eurostat's guidelines, the households from wave $t-1$ that are passed to wave $t>1$ for follow-up are: (i) those interviewed, and (ii) those not interviewed because of non-contact, physical incapacity or inability to respond, or refusal which is considered to be "less than final". To the follow-ups are added newly formed households containing at least one sample person. Excluded from follow-up are the households that gave a final refusal to respond in wave $t-1$ and those that have moved to a country outside the EU or have been entirely institutionalized. These households are only "traced" for future follow-up in case they return to the study population. Sample addresses or households found to be ineligible or nonexistent are dropped. Starting from wave 3 , households not interviewed in two consecutive waves are also dropped.

Turning to persons, sample members are always followed within the EU until they die or become ineligible. Sample persons who have moved to a country outside the EU or have been institutionalized are "traced" for future follow-up in case they return to the study population. Like the PSID, nonsample persons are not followed if they move into a household not containing sample persons. ${ }^{4}$

These following rules have been significantly modified in some countries, especially between the first and the second wave. In the UK, in particular, it was decided for budgetary reasons to follow only interviewed households with complete personal interviews, thus resulting in a severe depletion of the sample. Further, most countries did not follow people who moved to another EU country.

Table 2 shows the development of the number of households with household interview completed in the first three waves of the ECHP. As a comparison, we also report the household sample dynamics in the first three waves of the BHPS, the GSOEP, Luxembourg's PSELL and the PSID. In terms of sample dynamics, the ECHP compares well with the other panels, except possibly the BHPS. For most countries, the decline in the ECHP sample size is moderate, and for some of them (Italy and Portugal) we even observe small increases in the number of interviewed households. The main exceptions are Ireland and the UK, where the ECHP sample has been shrinking fast across successive waves due to substantial attrition.

\subsection{Questionnaire}

A key feature of the ECHP is the adoption of a common questionnaire (the "Community questionnaire") centrally designed by Eurostat. The ques-

\footnotetext{
${ }^{4}$ This is different from the GSOEP, where all persons (both sample and nonsample) are followed once in the panel.
} 
Table 2. Number of household interviews completed in the first three waves of the ECHP and of other household panel surveys

\begin{tabular}{|c|c|c|c|c|c|c|}
\hline & & \multicolumn{3}{|c|}{ Sample size } & \multicolumn{2}{|c|}{ Index $($ wave $1=100)$} \\
\hline & & Wave 1 & Wave 2 & Wave 3 & Wave 2 & Wave 3 \\
\hline BHPS & & 5511 & 5527 & 5528 & 1.003 & 1.003 \\
\hline \multirow{14}{*}{ ECHP } & Austria & & 3380 & 3291 & & \\
\hline & Belgium & 3490 & 3367 & 3210 & .965 & .920 \\
\hline & Denmark & 3482 & 3223 & 2955 & .926 & .849 \\
\hline & Finland & & & 4139 & & \\
\hline & France & 7344 & 6722 & 6600 & .915 & .899 \\
\hline & Germany & 4968 & 4688 & 4593 & .944 & .925 \\
\hline & Greece & 5523 & 5220 & 4908 & .945 & .889 \\
\hline & Ireland & 4048 & 3584 & 3173 & .885 & .784 \\
\hline & Italy & 7115 & 7128 & 7132 & 1.002 & 1.002 \\
\hline & Luxembourg & 1011 & 962 & 933 & .952 & .923 \\
\hline & Netherlands & 5187 & 5110 & 5179 & .985 & .998 \\
\hline & Portugal & 4881 & 4916 & 4850 & 1.007 & .994 \\
\hline & Spain & 7206 & 6522 & 6268 & .905 & .870 \\
\hline & UK & 5779 & 4548 & 3775 & .787 & .653 \\
\hline \multirow[t]{2}{*}{ GSOEP } & West sample & 5921 & 5322 & 5090 & .899 & .860 \\
\hline & East sample & 2179 & 2030 & 2020 & .932 & .927 \\
\hline PSELL & & 2012 & 1793 & 1644 & .891 & .817 \\
\hline PSID & & 4802 & 4460 & 4655 & .929 & .969 \\
\hline
\end{tabular}

tionnaire focuses on household and personal income, especially earnings and public transfers, but also collects detailed information on demographic characteristics, labor force behavior (including job search activities), health, education and professional training, housing, migration and geographical mobility, at both the household and the personal level.

The questionnaire consists of a household register, mainly for record keeping and control of the sample, a household questionnaire submitted to a "reference person" (usually the household head or the spouse/partner of the head), and a personal questionnaire submitted to all eligible household members (that is, aged 16 or older). ${ }^{5}$ Tables 3 and 4 summarize the structure of wave 1 questionnaire. For a detailed presentation of the questionnaire, see Eurostat (1996a) and (1996b).

The complexity of a questionnaire is known to negatively affect response rates and data quality. Important dimensions of complexity are: (i) how long it takes to fill the questionnaire, (ii) the wording of the questions, (iii) the reference period for the questions, and (iv) the branching and skip patterns. We now provide some evidence on each of these four dimensions.

The median duration of household interviews is between 15 and 20 minutes, except for wave 1 in France where, because of substantial additions

\footnotetext{
${ }^{5}$ This is unlike the PSID, where the head (or the spouse/partner of the head) serves as the sole respondent and the most detailed information is collected for the head and, since the late 1970s, for the spouse/partner.
} 
Table 3. Structure of the Community version of the wave 1 household questionnaire

\section{MIGRATION AND HOUSING}

- Duration of current stay, previous place of residence, reasons for moving.

- Type of house, rooms, amenities and problems.

- Tenure.

\begin{tabular}{|ll|}
\hline $\begin{array}{l}\text { IF HOME OWNER } \\
\text { - Outstanding mortgage or housing loan, } \\
\begin{array}{l}\text { whether this is a burden, housing allowance } \\
\text { received. }\end{array}\end{array}$ & $\begin{array}{l}\text { IF TENANT OR SUBTENANT } \\
\text { additional charges, whether housing costs } \\
\text { are a burden, housing allowance received. }\end{array}$ \\
\hline
\end{tabular}

ECONOMIC SITUATION

- Whether has, wants and can afford various durable goods.

- Debt burden.

- Whether able to make ends meet.

- Whether can afford certain necessities.

- Whether unable to meet repayment committments on debt.

HOUSEHOLD INCOME DURING LAST CALENDAR YEAR

- Total household income.

- Household related components of income.

- Views about general economic situation.

- Duration of the interview.

to the standard version of the questionnaire, median duration was 40 minutes. Personal interviews tend to last a little longer. Median duration usually ranges between 20 and 30 minutes, is a little shorter in France, Italy and Luxembourg (between 15 and 20 minutes), and somewhat longer in Belgium (between 35 and 40 minutes).

Subjective and sensitive wording questions are not infrequent. Examples include the following: "To what extent are housing costs [or debt] a burden to you?", "Thinking of your household's total monthly income, is your household able to make ends meet?", "In your opinion, what is the very lowest net monthly income that your household would have to have in order to make ends meet?", "How satisfied are you with your present situation in the following areas: work or main activity, financial situation, housing situation, amount of available leisure time?". The available evidence shows that nonresponse to this kind of questions tends to be high (Verma 1995).

The reference period varies considerably depending on the question being asked. For personal characteristics, it is the day of the interview. For economic activity (occupational status, etc.), it is the last 7 days before the interview. For absence from work, it is the last 4 working weeks before the interview. For income and income sources, it is the last calendar year. For cash and non-cash social assistance, it is each month in the last calendar year.

Finally, the ECHP questionnaire makes extensive use of branching and skip patterns, which may create problems if interviewers are not sufficiently well trained.

The basic questionnaire has undergone a few changes, both across countries and over time. One set of changes reflects the effort by the NDUs to translate and adapt the basic questionnaire to the specific conditions of each country. 
Table 4. Structure of the Community version of the wave 1 individual questionnaire

\begin{tabular}{|c|c|}
\hline $\begin{array}{l}\text { IF WORKING AT LEAST } 15 \text { HOURS A WEEK } \\
\text { - Status in employment; when started; how found } \\
\text { work; unemployment before present work. } \\
\text { - If worked before: When and why stopped; com- } \\
\text { parison with present work. } \\
\text { - Present job profile. } \\
\text { - If in paid employment: Net and gross earnings; } \\
\text { employer's contribution to pension; other services } \\
\text { offered by the employer. } \\
\text { - Satisfaction with present job; absences from } \\
\text { work; secondary job; whether looking for } \\
\text { additional/different work. }\end{array}$ & $\begin{array}{l}\text { ELSE } \\
\text { - Type of activity, and training if any. } \\
\text { job profile. } \\
\text { - If seeking work: Availability for } \\
\text { work. } \\
\text { - If ever had work as main activity: } \\
\text { Year when stopped. } \\
\text { - If stopped working after 1979: Profile } \\
\text { of last job. }\end{array}$ \\
\hline
\end{tabular}

SOCIAL RELATIONS AND RESPONSIBILITIES

- Presence of others during the interview.

- Daily activities.

- Social relations.

ACTIVITY DURING LAST CALENDAR YEAR

- Education and training during last calendar year.

- Activity status: Month-by-month changes in main activity status; whether also did any casual work during the year.

\section{PERSONAL INCOME DURING LAST CALENDAR YEAR}

- Net and gross income from main employment; overtime payments and similar; special payments and allowances received.

- Income from self-employment.

- Social protection benefits classified according to Eurostat's ESSPROS classification.

- Other income including capital and savings interest.

- Direct pension contributions.

\section{HEALTH}

- General health status, hospitalization and visits to doctor.

- Medical expenses, contributions paid.

\section{BIOGRAPHICAL INFORMATION}

- Demographic and migration.

- Early work experience.

- Satisfaction with work, financial and housing situation, leisure time.

- Duration of the interview.

Although most national versions follow very closely the Community version, important departures have occurred in four countries (Eurostat 1996b, 2000): (i) Belgium and Ireland made substantial additions to the basic questionnaire in wave 1, with a negative impact on response rates, (ii) France introduced major modifications to allow comparisons with other national surveys, (iii) the range of questions asked is much smaller in the Netherlands where the ECHP is based on the existing national panel, (iv) starting from wave 4, similar problems occur for Germany, Luxembourg and the UK, where existing national panels have replaced the original ECHP survey. 
Over time, the basic questionnaire has undegone a number of changes that reflect the experience on the field and new requirements by the European Commission and Eurostat itself. The main changes are: (i) the introduction of a "relationship matrix" to better represent the household structure, (ii) a new section on children under age 16, (iii) the addition of questions on active job search, (iv) the recasting of questions on health status and pensions, (v) the broadening of the section on education and vocational training, and (vi) the addition of a new category of employment status ("training under special scheme related to employment").

\subsection{Fieldwork}

Because the information on income refers to the last calendar year, the original plan was to carry out the fieldwork early each year, in coincidence with preparation of income tax returns by the households. Wave 1, however, did not conform to this standard. In Belgium, Denmark, Netherlands and Portugal, fieldwork began in the Spring and was completed by October. In Germany, Ireland, Italy and the UK, fieldwork was carried out in the second half of 1994, with a tail in January 1995 for Germany and Ireland. In France, Greece, Luxembourg and Spain it was concentrated in the last quarter of 1994. Lack of syncronization between countries persisted in the subsequent waves of the ECHP, with fieldwork carried out in the first half of the year in Finland, in the second and third quarter in Belgium, Denmark and the Netherlands, and in the second half of the year in the remaining countries.

The interviewing method recommended by Eurostat is face-to-face personal interviewing. Other interviewing methods have been used, however, such as self-completed by the respondent, telephone, and proxy (for personal interviews only). Eurostat recommends the use of proxy interviewing as "last resort in a restricted range of cases", such as temporary absence, illness or language problems. This recommendation has not been followed very closely and in some countries, such as Italy, proxy respondents represent between 10 and 15 percent of total personal interviews.

In four countries, namely Greece, Portugal, Netherlands and the UK, interviews are carried out, at least partly, using computer assisted personal interviewing (CAPI). All other countries rely instead on the conventional "paper and pencil" method. Eurostat has been rather lukewarm about CAPI, fearing it could restrict the flexibility of interviewing, thereby reducing response rates and full partecipation of all household members.

In order to reduce inter-wave inconsistencies, Eurostat recommends feeding forward a certain amount of information, mainly demographic, from one wave to the next. Respondents should verify this information and update it, if necessary. Because of fear of suppressing genuine changes, Eurostat decided not to extend forward feeding to include labor force and income details. On the other hand, Eurostat recommends the NDUs using CAPI to incorporate longitudinal plausibility checks into their computer programs.

Little is known about the criteria for selecting the interviewers, their training in order to get valid responses on sensitive items, and the instructions in case of refusal to respond to certain questions. Although Eurostat recommends monitoring of interviewers through post-interview verification, it is not known whether and to what extent this is actually done. 


\subsection{Data editing}

Data from each wave are first checked and edited by the NDUs using checking programs provided by Eurostat as well as national standard checking rules. After receiving the datasets, Eurostat carries out its own checks. The NDUs are informed about the results of these checking procedures. In some cases, they are requested to review the data and edit items where possible.

The ECHP has not been supplemented by reinterview programs to measure the reliability of the responses. An alternative way of estimating data quality, easily implementable in the ECHP, would be to collect information for an overlapping period in successive interviews (O’Muircheartaigh 1989).

Eurostat's minimalist approach to forward feeding of information from one wave to another implies that, in addition to cross-sectional editing for each wave, longitudinal editing is also necessary to correct longitudinally inconsistent or implausible responses.

\section{Data access and organization}

The micro-data files collected by the NDUs are sent to Eurostat and stored in the so-called Production Data Base (PDB). Because the PDB contains information considered confidential on the basis of EU Statistical Law and has a rather complex structure, its access is confined to Eurostat and the NDUs. People interested in the ECHP may negotiate with Eurostat the purchase of the Users' Data base (UDB), which is an anonymized and user-friendly version of the data.

The UDB has been made available only recently. The first longitudinal UDB, covering waves 1 and 2, was released in December 1998, three years after completion of fieldwork for wave 2. A longitudinal UDB covering the first three waves has been released in December 1999, and the one covering the first four waves is expected in the Spring of 2001. The availability of these data is restricted both by their price (about $\$ 8,000$ for regular users) and the strict conditions of use specified by the contract with Eurostat.

\subsection{Organization of the UDB}

In the UDB, variables are reorganized and standardized across waves, no more strictly reflecting the structure of the questionnaire. The UDB also contains "derived variables" constructed from the original ones.

The UDB consists of four files for each wave: a "Register file", a "Relationship file", a "Household file", and a "Personal file". The Register file covers all persons currently living in households with a completed household interview. The Relationship file specifies the relationships between household members and contains one record for each pair of persons in the household. The Household file contains the information from the household interview and has one record for each household with household interview completed. The Personal file contains the information from the personal interview and has one record for each personal interview completed. Households and persons are identified through identification numbers that are fixed and unique within country. The UDB also contains a "Link file" which enables 
tracing of individuals ever in the survey ${ }^{6}$ and a file with aggregate variables for each country (population figures, purchasing power parities and exchange rates).

\subsection{Anonymization criteria}

Construction of the UDB required extensive negotiations with the NDU's and various bodies of the European Commission. The anonymization criteria adopted restrict the information available on age, occupation and industry of employment, income, geographical mobility and region of residence. The criteria are not the same for all countries and are generally more severe for Germany and the Netherlands.

Specifically, information on the upper end of the age distribution has been restricted by bottomcoding year of birth at 1909 (1924 for Germany). Information on school attainments have been collapsed to the three-category ISCED level. Occupational codes and sector of activity are restricted to a level of aggregation intermediate between 1 and 2 digits. Income components are aggregated at an intermediate level and converted to annual net amounts. No information on migration trajectory is available for Germany, whereas the information on foreign country of birth and last foreign country of residence is not available for Germany, Greece and the Netherlands. Finally, no regional information is available for Germany and the Netherlands, whereas for all other countries, except Finland and Portugal, the breakdown is at the coarse levl of NUTS 1.

\section{Nonresponse}

Nonresponse is a typical problem with household surveys, and the ECHP is no exception. Because of nonresponse, the available data do not conform to the ideal case of complete data, for which standard statistical methods and software packages are designed. It is important to notice that nonresponse not only implies an efficiency loss relative to the complete-data case, but also makes identification of population parameters problematic. As shown by Horowitz and Manski (1998), the seriousness of the problem is directly proportional to the amount of nonresponse.

It is useful to distinguish between the following four types of nonresponse, all of which are present in the ECHP:

1. Unit (or complete) nonresponse: It occurs when no information is available from a sample unit. It may be caused by refusal or inability of the unit to participate, or by a missing questionnaire.

2. Item (or partial) nonresponse: It occurs when a unit refuses to answer, or fails to provide a useful response, to a particular question included in the survey.

3. Attrition: It is a special kind of unit nonresponse arising in panel data, and is defined as failure to obtain data from a sample unit at any wave after it has been selected into the survey.

\footnotetext{
${ }^{6}$ Unfortunately, the link file does not provide complete records of persons lost to the sample as a result of noninterview at the household stage, which makes it difficult to reconstruct the evolution of the sample.
} 
4. New entry: It is another kind of unit nonresponse arising in panel data, and is defined as failure to obtain data from a sample unit at any wave before its addition to the initial sample.

Like most public-use panel surveys, the ECHP deals with unit nonresponse, sample attrition and new entry by providing weights for the response cases, and with item nonresponse by imputing missing values. Eurostat is devoting a considerable amount of its resources to weighting and imputations, and the long delay in releasing the data partly reflects the difficulties encountered.

After discussing unit and item nonresponse in Sections 4.1 and 4.2, we turn to sample attrition and new entry, which are the main sources of the ECHP sample dynamics. Some of the issues raised here are not new, and have already been discussed with reference to the PSID (see e.g. Becketti et al. 1988, Duncan \& Hill 1989, Lillard 1989, and Fitzgerald, Gottschalk \& Moffitt 1997).

\subsection{Unit nonresponse}

Table 5 shows household response rates in the first three waves of the ECHP. Given the difficulty of computing response rates from the UDB, we rely on tabulations provided by Eurostat. ${ }^{7}$ As a comparison, we also report household

Table 5. Household response rates in the first three waves of the ECHP and other household panel surveys. Source: Eurostat (1997b)

\begin{tabular}{|ll|lll|}
\hline & & Wave 1 & Wave 2 & Wave 3 \\
\hline BHPS & & .736 & .889 & .877 \\
\hline & Belgium & .844 & .873 & \\
& Denmark & .624 & .828 & .767 \\
& France & .795 & .896 & \\
& Germany & .477 & .920 & .955 \\
& Greece & .901 & .885 & .874 \\
& Ireland & .558 & .818 & .817 \\
& Italy & .907 & .909 & .907 \\
& Luxembourg & .407 & .940 & .900 \\
& Netherlands & .875 & .889 & .916 \\
& Portugal & .889 & .904 & .968 \\
& Spain & .670 & .869 & .843 \\
& UK & .716 & .843 & .856 \\
\hline GSOEP & West sample & .622 & & \\
\hline PSELL & & .650 & & \\
\hline PSID & & .760 & .890 & .970 \\
\hline
\end{tabular}

\footnotetext{
${ }^{7}$ Household response rates are defined as the ratio of the number of interviewed households to the target number for interview. For the first wave, the latter is just the number of households selected into the sample, excluding the cases which turned out to be nonexistent or otherwise ineligible. For the second and third waves, it is the number of households forwarded from the previous wave, minus those no longer existing, plus the newly formed ones.
} 
response rates in the first three waves of the BHPS, the GSOEP, the PSELL, and the PSID. Household nonresponse accounts for most of the nonresponse, as nonresponse of individuals within interviewed households never exceeds 3 percent and displays little variation across countries (Eurostat 2000).

As is typical with household panels, response rates differ substantially between the first and subsequent waves of the ECHP. The overall household response rate in wave 1 is 72 percent and is comparable to the one observed in the initial wave of the other panels considered. More striking, however, is the large variation across countries. Belgium, France, Greece, Italy, Netherlands, and Portugal are well above average, the UK is about average, whereas Austria, Denmark, Germany, Ireland, Luxembourg, and Spain are below average, with response rates in Germany and Luxembourg that are about half the ones observed in Greece and Italy. It is hard to explain such a wide crosscountry variation. The very high response rates in Greece and Italy may partly be due to the fact that survey participation is compulsory in these two countries. On the other hand, the low response rates in Germany and Luxembourg largely reflect outright refusal to participate.

Like for the other panels, response rates in later waves of the ECHP tend to be higher than in the initial one, often notably as in the case of Germany and Luxembourg. ${ }^{8}$ Moreover, while there is no correlation between response rates in the first and the second wave, the correlation between response rates in the second and third wave is instead positive and very strong. Figure 1 shows that the differences in household response rates between the first two waves of the ECHP are inversely proportional to the initial response rates. As a result, we observe a considerable reduction of the cross-country variability of response rates between the first and the second wave of the ECHP, although not between the second and the third.

Eurostat (1996a) presents the results of two evaluation studies focusing on the effect of unit nonresponse on the cross-sectional representativeness of
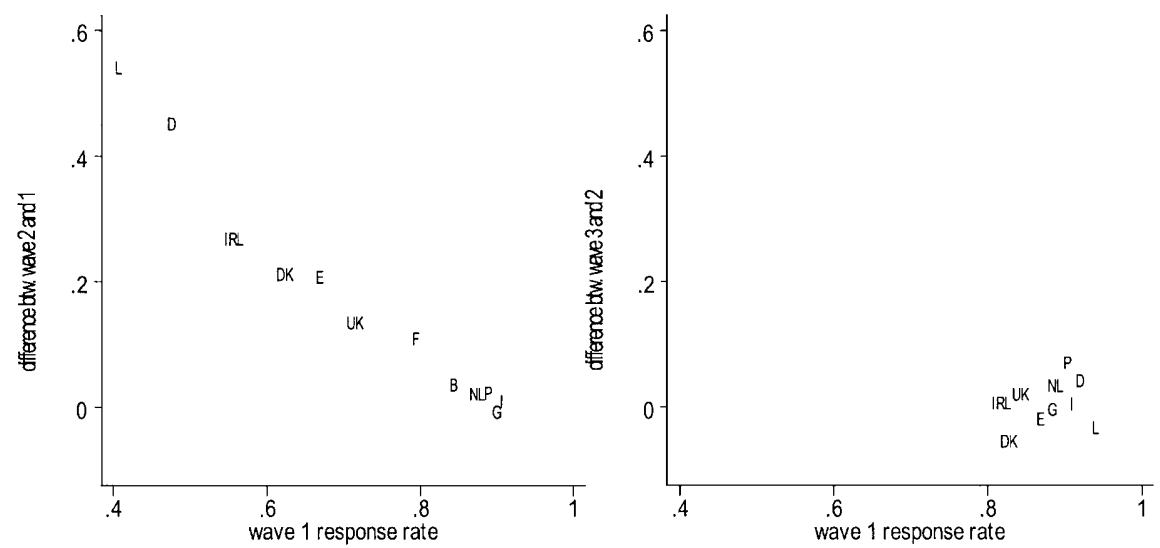

Fig. 1. Differences in household response rates between successive waves of the ECHP.

\footnotetext{
${ }^{8}$ This phenomenon may help explain the relatively high response rates in wave 1 for Belgium and the Netherlands, as wave 1 of the ECHP corresponds in these two countries to later waves of existing national panels. The initial response rate for both panels was about 50 percent.
} 
the initial wave of the ECHP. These studies, carried out for Denmark and the Netherlands, compare estimates of the same population characteristics computed from the ECHP and from external sources. Both studies find that the effects of nonresponse are small. However, they only compare estimates of population means and proportions, not of regression relationships.

\subsection{Item nonresponse}

In evaluating item nonresponse in the ECHP, three aspects must be taken into account. First, computing nonresponse rates is complicated by the presence of branching and skip patterns in the questionnaire, which requires identifying precisely the "universe" for each question.

Second, in the case of income sources, various degrees of nonresponse are possible. For example, although both gross and net earnings amounts are requested, respondents often report only one of them. In some cases, when the actual income amount is not specified, the questionnaire allows the response to take the form of a range. For most types of income, the questionnaire asks for the monthly average, along with the number of months received. If these are not specified, then the annual total may be recorded.

Third, it is important to distinguish between "missing at random" and "nonignorable nonresponse", depending on whether the probability of item nonresponse depends only on exogenous covariates or also upon the value of the variable of interest (see Greenlees, Reece \& Zieschang 1982, Little 1982, and Little \& Rubin 1987). Although the distinction is not made by Eurostat, it is crucial for the validity of the imputation methods discussed in Section 6.

To provide a quantitative indication of the degree of item nonresponse for income components, Table 6 shows the fraction of households with positive amounts of a given income component (column A), the fraction for which the income component has been at least partly imputed (column B), and the fraction for which values are missing even after imputation (column $\mathrm{C}$ ). The data are simple averages of country specific proportions. The table reveals that partial nonresponse on specific income components is substantial for selfemployment earnings and capital income, and is non negligible for other income components, such as wage and salary earnings and private transfers received. As a result, total net household income has been imputed, at least partly, for more than one third of the households. Further, this percentage has been rising through time.

Table 7 focuses on total net household income and shows the extent of item nonresponse by country. Non response appears to be highest in Belgium and France, and lowest in Ireland and the Netherlands. In Belgium, France, Greece, Italy, Netherlands, Portugal and the UK there is a clear trend towards increasing nonresponse.

\subsection{Attrition}

Attrition affects, more or less seriously, most household panels. It depends on both individual behavior and the procedures followed by the agency collecting the data. This distinction is important but is often ignored in the literature. 
Table 6. Item nonresponse by income component. Column A shows the fraction of households with positive income component, column B shows the fraction of households for which some inputation has been made, whereas column $\mathrm{C}$ shows the fraction of households with missing income component. The data are simple averages of country specific proportions

\begin{tabular}{|c|c|c|c|c|c|c|c|c|c|}
\hline & \multicolumn{3}{|c|}{ Wave 1} & \multicolumn{3}{|c|}{ Wave 2} & \multicolumn{3}{|c|}{ Wave 3} \\
\hline & A & B & $\mathrm{C}$ & A & B & $\mathrm{C}$ & A & B & $\mathrm{C}$ \\
\hline Total net household income & .988 & .344 & .012 & .991 & .369 & .009 & .991 & .374 & .009 \\
\hline $\begin{array}{l}\text { Net income from work } \\
\text { - Wage and salary earnings } \\
\text { - Self-employment earnings }\end{array}$ & $\begin{array}{l}.636 \\
.155\end{array}$ & $\begin{array}{l}.110 \\
.092\end{array}$ & $\begin{array}{l}.012 \\
.012\end{array}$ & $\begin{array}{l}.642 \\
.160\end{array}$ & $\begin{array}{l}.115 \\
.094\end{array}$ & $\begin{array}{l}.009 \\
.009\end{array}$ & $\begin{array}{l}.647 \\
.164\end{array}$ & $\begin{array}{l}.091 \\
.100\end{array}$ & $\begin{array}{l}.009 \\
.009\end{array}$ \\
\hline $\begin{array}{l}\text { Non-work private income } \\
\text { - Capital income } \\
\text { - Property/rental income } \\
\text { - Private transfers received }\end{array}$ & $\begin{array}{l}.288 \\
.065 \\
.065\end{array}$ & $\begin{array}{l}.159 \\
.002 \\
.010\end{array}$ & $\begin{array}{l}.010 \\
.012 \\
.010\end{array}$ & $\begin{array}{l}.339 \\
.063 \\
.069\end{array}$ & $\begin{array}{l}.223 \\
.002 \\
.009\end{array}$ & $\begin{array}{l}.008 \\
.009 \\
.008\end{array}$ & $\begin{array}{l}.313 \\
.066 \\
.071\end{array}$ & $\begin{array}{l}.184 \\
.002 \\
.071\end{array}$ & $\begin{array}{l}.008 \\
.009 \\
.008\end{array}$ \\
\hline $\begin{array}{l}\text { Social insurance receipts } \\
\text { - Unemployment benefits } \\
\text { - Old age/survivors' benefits } \\
\text { - Family related allowances } \\
\text { - Sickness/invalidity benefits } \\
\text { - Education-related allowances } \\
\text { - Any other personal benefits } \\
\text { - Social assistance } \\
\text { - Housing allowance }\end{array}$ & $\begin{array}{l}.119 \\
.339 \\
.257 \\
.098 \\
.030 \\
.029 \\
.034 \\
.082\end{array}$ & $\begin{array}{l}.012 \\
.038 \\
.018 \\
.010 \\
.004 \\
.004 \\
.000 \\
.002\end{array}$ & $\begin{array}{l}.012 \\
.012 \\
.010 \\
.010 \\
.010 \\
.010 \\
.012 \\
.012\end{array}$ & $\begin{array}{l}.116 \\
.352 \\
.269 \\
.096 \\
.031 \\
.026 \\
.031 \\
.074\end{array}$ & $\begin{array}{l}.007 \\
.030 \\
.015 \\
.011 \\
.005 \\
.002 \\
.000 \\
.001\end{array}$ & $\begin{array}{l}.009 \\
.009 \\
.008 \\
.008 \\
.008 \\
.008 \\
.009 \\
.009\end{array}$ & $\begin{array}{l}.119 \\
.350 \\
.282 \\
.096 \\
.039 \\
.027 \\
.032 \\
.075\end{array}$ & $\begin{array}{l}.008 \\
.023 \\
.014 \\
.009 \\
.006 \\
.004 \\
.000 \\
.001\end{array}$ & $\begin{array}{l}.009 \\
.009 \\
.008 \\
.008 \\
.008 \\
.008 \\
.009 \\
.009\end{array}$ \\
\hline Monthly wages (current) & .565 & .072 & .002 & .596 & .055 & .002 & .600 & .017 & .002 \\
\hline
\end{tabular}

Table 7. Nonresponse on total net household income by country. Column A shows the fraction of households with positive total net household income, column B shows the fraction of households for which some imputation has been made, whereas column $\mathrm{C}$ shows the fraction of households with missing total net household income

\begin{tabular}{|l|rcc|ccc|ccc|}
\hline & \multicolumn{3}{|c|}{ Wave 1 } & \multicolumn{3}{c|}{ Wave 2 } & \multicolumn{3}{c|}{ Wave 3 } \\
\cline { 2 - 10 } & $\mathrm{A}$ & $\mathrm{B}$ & $\mathrm{C}$ & $\mathrm{A}$ & $\mathrm{B}$ & $\mathrm{C}$ & $\mathrm{A}$ & $\mathrm{B}$ & $\mathrm{C}$ \\
\hline Austria & & & & .996 & .405 & .004 & .997 & .296 & .003 \\
Belgium & .985 & .387 & .015 & .988 & .447 & .012 & .989 & .518 & .011 \\
Denmark & .999 & .411 & .001 & .997 & .360 & .003 & .999 & .287 & .001 \\
Finland & & & & & & & .998 & .402 & .002 \\
France & .993 & .456 & .007 & .995 & .610 & .005 & .995 & .630 & .005 \\
Germany & .986 & .433 & .014 & .994 & .400 & .006 & .995 & .373 & .005 \\
Greece & .992 & .330 & .008 & .991 & .346 & .009 & .989 & .480 & .011 \\
Ireland & .993 & .313 & .007 & .996 & .207 & .004 & .997 & .217 & .003 \\
Italy & .967 & .331 & .033 & .982 & .369 & .018 & .985 & .423 & .015 \\
Luxembourg & 1.000 & .362 & .000 & .994 & .409 & .006 & .995 & .393 & .005 \\
Netherlands & .986 & .212 & .014 & .977 & .233 & .023 & .976 & .249 & .024 \\
Portugal & .980 & .283 & .020 & .990 & .318 & .010 & .991 & .354 & .009 \\
Spain & .991 & .299 & .009 & .987 & .323 & .013 & .977 & .237 & .023 \\
UK & .990 & .312 & .010 & .996 & .370 & .004 & .997 & .374 & .003 \\
\hline
\end{tabular}


Table 8. Household attrition rates in the first three waves of the ECHP and other household panel surveys

\begin{tabular}{|ll|lll|}
\hline \multirow{2}{*}{} & & \multicolumn{3}{|c|}{ Attrition rate between waves } \\
\cline { 3 - 5 } & & 1 and 2 & 2 and 3 & 1 and 3 \\
\hline \multirow{2}{*}{ BHPS } & .116 & .089 & .177 \\
\hline \multirow{2}{*}{ ECHP } & Belgium & .087 & .089 & .151 \\
& Denmark & .140 & .147 & .233 \\
& France & .112 & .075 & .158 \\
& Germany & .073 & .048 & .112 \\
& Greece & .097 & .088 & .167 \\
& Ireland & .153 & .148 & .273 \\
& Italy & .059 & .051 & .087 \\
& Luxembourg & .065 & .057 & .118 \\
& Netherlands & .089 & .071 & .122 \\
& Portugal & .047 & .061 & .089 \\
& Spain & .126 & .094 & .185 \\
& UK & .238 & .193 & .377 \\
\hline \multirow{2}{*}{ GSOEP } & West sample & .124 & .098 & .210 \\
& East sample & .089 & .082 & .162 \\
\hline \multirow{2}{*}{ PSELL } & & .153 & .129 & .262 \\
\hline \multirow{2}{*}{ PSID } & SRC sample & .145 & & .172 \\
& SEO sample & .091 & & .135 \\
\hline
\end{tabular}

Table 8 presents household attrition rates in the first three waves of the ECHP. ${ }^{9}$ As a comparison, we also report household attrition rates in the first three waves of the BHPS, the GSOEP, the PSELL, and the PSID.

Attrition rates between the first and the second wave of the ECHP vary considerably across countries. They are highest in the UK ( 24 percent) and Ireland (15 percent), lowest ( 6 percent or less) in Italy and Portugal, and average to about 10 percent in the other 9 countries. Except for the UK and Ireland, these percentages are in line with the ones observed for the other household panels considered. The very high attrition rate in the UK partly reflects the decision by the British NDU to follow only interviewed households with complete personal interviews.

Household attrition rates between the second and the third wave tend to be slightly higher, with the notable exceptions of Spain and the UK where attrition rates have instead fallen (but still remain very high in the UK). Finally, a comparison of Tables 5 and 8 shows the existence of a negative relationship between attrition rates and response rates in the ECHP.

Turning to individuals, it is useful to distinguish between nonmonotone and monotone attrition, depending on whether or not a survey participant who at some point leaves, returns to the sample at a later date. Since both types are possible in the ECHP, there are four kinds of sample participants:

\footnotetext{
9 The household attrition rate between wave $s$ and wave $t>s$ is defined as one minus the ratio between the number of households interviewed in both waves and the number of households interviewed in wave $s$.
} 
Table 9. Patterns of sample participation in the first three waves of the ECHP

\begin{tabular}{|l|ccccccc|}
\hline & \multicolumn{7}{|c|}{ Patterns of sample participation } \\
\cline { 2 - 8 } & 111 & 110 & 100 & 101 & 011 & 010 & 001 \\
\hline Belgium & .739 & .076 & .080 & .011 & .043 & .014 & .037 \\
Denmark & .675 & .112 & .099 & .023 & .040 & .020 & .031 \\
France & .757 & .061 & .090 & .017 & .033 & .008 & .035 \\
Germany & .841 & .045 & .069 & .005 & .023 & .002 & .016 \\
Greece & .733 & .073 & .085 & .006 & .066 & .009 & .029 \\
Ireland & .611 & .120 & .175 & .006 & .038 & .016 & .035 \\
Italy & .806 & .045 & .041 & .015 & .053 & .006 & .033 \\
Luxembourg & .825 & .052 & .062 & .003 & .024 & .005 & .029 \\
Netherlands & .742 & .053 & .070 & .017 & .055 & .008 & .056 \\
Portugal & .777 & .058 & .039 & .011 & .059 & .010 & .045 \\
Spain & .689 & .084 & .113 & .023 & .044 & .009 & .039 \\
UK & .575 & .142 & .223 & .001 & .020 & .013 & .025 \\
\hline
\end{tabular}

full-time participants (no attrition), base-year participants with a monotone attrition pattern, base-year participants with a nonmonotone attrition pattern, and non-base-year participants that have been added to the sample.

Table 9 shows the patterns of sample participation in the first three waves of the ECHP. Overall, there are 7 possible patterns, each one represented by a sequence of 1's and 0's denoting, respectively, participation and nonparticipation to a given wave. Thus, the sequence " 111 " corresponds to full-time participants, the sequences " 110 " and " 100 " correspond to base year-participants with monotone attrition patterns, "101" corresponds to base-year participants with nonmonotone attrition pattern, whereas "011", " 010 " and " 001 " correspond to non-base-year participants that have been added to the sample.

The importance of the various patterns of sample participation varies widely across countries. Full-time participation is by far the most frequent, followed by monotone attrition. The fraction of full-time participants ranges between a maximum of 84 percent in Germany and a minimum of 58 percent in the UK, while monotone attrition is very important in Ireland and the UK, where it represents more than 30 percent of sample participants.

Table 10 presents individual attrition rates in the first three waves of the ECHP. ${ }^{10}$ In general, individual attrition rates are slightly higher than household attrition rates. As for households, individual attrition rates are highest in Ireland and the UK and lowest in Italy and Portugal. With the exception of Belgium, Denmark and Portugal, individual attrition rates tend to decline across waves.

Simple calculations show that even moderate attrition rates may accumulate and become substantial over a few years. For example, a monotone attrition of 10 percent per year implies that 27 of the initial sample is lost after 3 years, 47 percent after 6 years and 61 percent after 9 years. When attrition is exogenous, that is, unrelated to the response variable of interest, this rapid

\footnotetext{
10 The individual attrition rate between wave $s$ and wave $t>s$ is defined as one minus the ratio between the number of individuals interviewed in both waves and the number of individuals interviewed in wave $s$.
} 
Table 10. Individual attrition and entry rates in the first three waves of the ECHP

\begin{tabular}{|l|lll|ll|}
\hline & \multicolumn{3}{|c|}{ Attrition rates } & \multicolumn{2}{c|}{ Entry rates } \\
\hline & 1 and 2 & 2 and 3 & 1 and 3 & 1 and 2 & 2 and 3 \\
\hline Belgium & .101 & .103 & .172 & .065 & .059 \\
Denmark & .134 & .156 & .232 & .071 & .070 \\
France & .116 & .080 & .163 & .047 & .062 \\
Germany & .077 & .051 & .119 & .027 & .024 \\
Greece & .101 & .093 & .176 & .085 & .041 \\
Ireland & .198 & .174 & .324 & .069 & .059 \\
Italy & .062 & .056 & .095 & .065 & .054 \\
Luxembourg & .069 & .063 & .121 & .032 & .037 \\
Netherlands & .098 & .071 & .139 & .073 & .084 \\
Portugal & .057 & .075 & .110 & .076 & .063 \\
Spain & .149 & .113 & .217 & .064 & .078 \\
UK & .238 & .207 & .388 & .044 & .042 \\
\hline
\end{tabular}

depletion of the sample creates efficiency problems but no bias. In a household panel, however, attrition is typically related to important events in a person's life, such as going to college, finding a new job, marriage or divorce, retirement, death. These events are, at the same time, the main object of study using panel data. Attrition cannot therefore be ignored, for it may lead to invalid inference, even when attrition rates are modest (see e.g. Becketti et al. 1988 and Peracchi \& Welch 1995).

Figure 2 presents individual attrition rates by sex and age for the nine largest countries (Austria, Denmark, Ireland, and Luxembourg are excluded). Data have been smoothed by taking averages across waves and adjacent years of age. Two features of the data emerge clearly. First, men tend to have slightly higher attrition rates than women. Second, for both men and women, the age profile of attrition tends to be U-shaped. Italy, Portugal and Spain show much less evidence of convexity in the age-attrition profiles, possibly because of the high fraction of adult children living with their parents.

Table 11 presents the estimated coefficients for logit models of attrition fitted, separately by country and wave, to the individual data. The model specification includes dummies for sex (female), age group (3 levels: aged less than 30, aged 45 to 59 , aged 60+), marital status (not married nor living in consensual union), and schooling (2 levels: secondary education and college). The baseline category is a man, aged 30-44, married or living in consensual union, with primary education only. The estimation results confirm the earlier finding of U-shaped age-attrition profiles. Attrition rates start up high for the youngest age group, reach a minimum for the age group 30-44, and then increase again with age. All other characteristics being equal, female are less likely to attrite, whereas people who are not married or have lower levels of schooling are more likely to attrite. Our estimates also indicate a tendency of attrition rates to decline across waves.

\subsection{New entry}

The other main source of sample dynamics in the first three waves of the ECHP is new entry of households and persons due to household formation, 


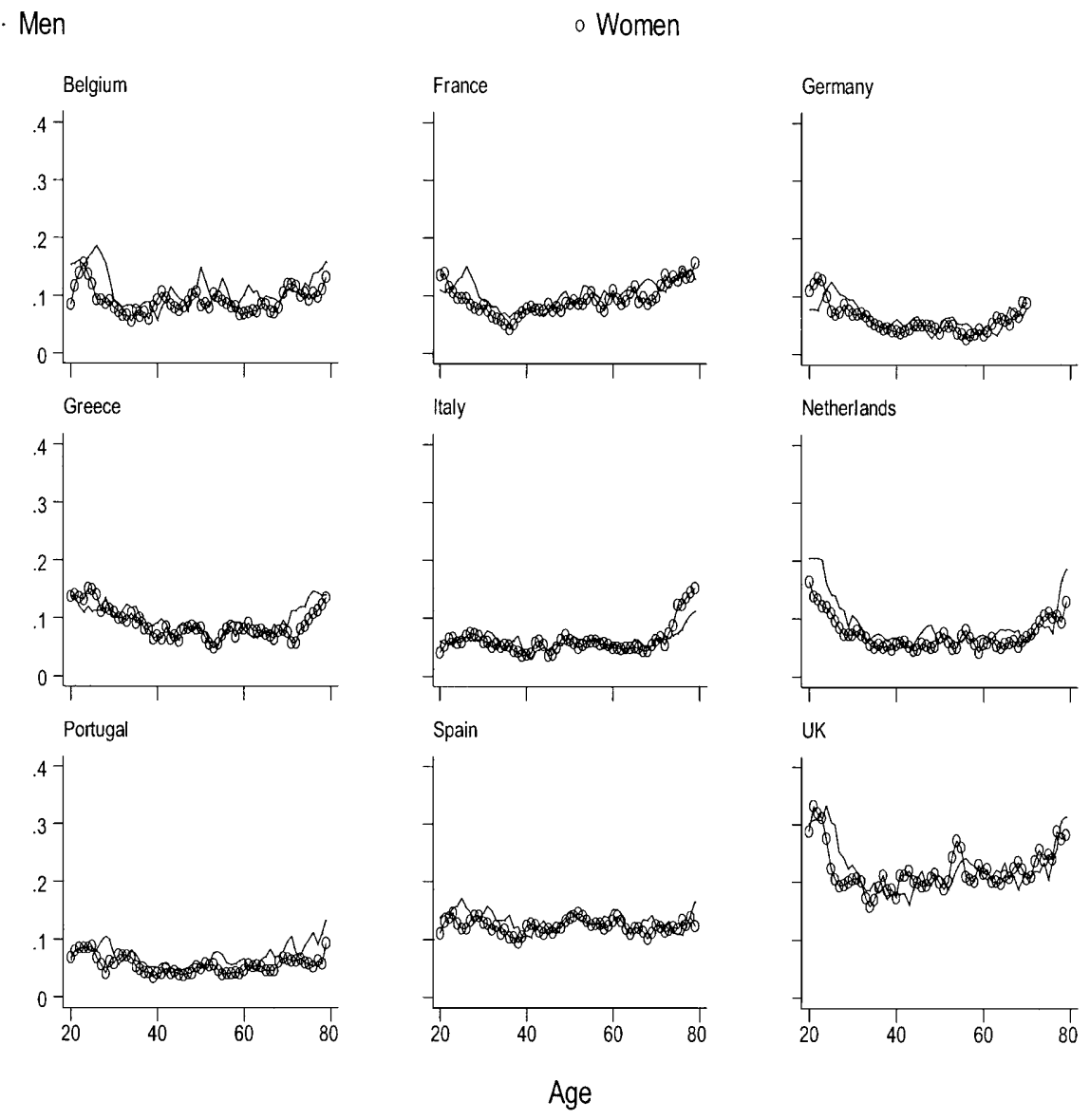

Fig. 2. Attrition rates by country, sex and age. Average across waves and adjacent years of age.

marriage, and previously ineligible persons becoming eligible. Depending on its characteristics, new entry may reduce or exacerbate the effects of attrition on the representativeness of the sample.

In the first three waves of the ECHP, entry of new households is entirely due to the split off of existing ones. Table 12 shows ECHP split off rates defined as the ratio between the number of new (split off) households and the number of households with the same identification number as in the last wave. Partly due to the different importance of the young and the elderly in the population, split off rates are highest in Denmark and Ireland, and lowest in Germany and Luxembourg.

Table 10 presents individual entry rates in the first three waves of the ECHP. ${ }^{11}$ Notice that entry rates between wave 2 and 3 also include re-entry

\footnotetext{
${ }^{11}$ The individual entry rate between wave $t$ and wave $t+1$ is defined as one minus the ratio between the number of individuals interviewed in both waves and the number of individuals interviewed in wave $t$.
} 


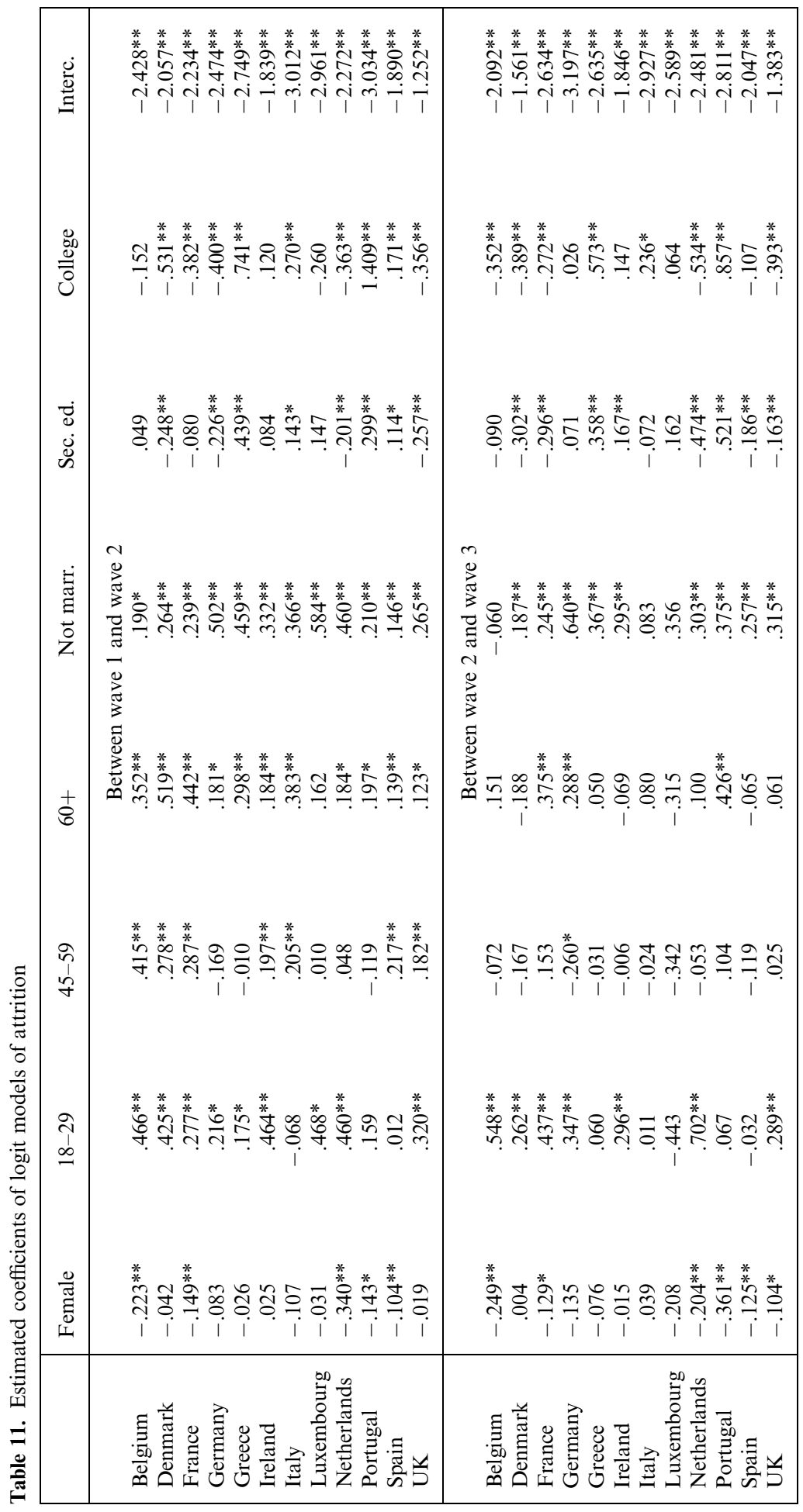


Table 12. Number of new (split off) households as a fraction of the number of households carried forward from the previous wave

\begin{tabular}{|l|ll|}
\hline & Wave 2 & Wave 3 \\
\hline Belgium & .028 & .029 \\
Denmark & .056 & .036 \\
France & .031 & .037 \\
Germany & .018 & .023 \\
Greece & .031 & .025 \\
Ireland & .045 & .039 \\
Italy & .035 & .035 \\
Luxembourg & .017 & .029 \\
Netherlands & & .036 \\
Portugal & .022 & .031 \\
Spain & .036 & \\
UK & .032 & \\
\hline
\end{tabular}

of individuals with nonmonotone attrition pattern. Entry rates are generally smaller than attrition rates, with the notable exception of Italy and Portugal where attrition and entry rates are of about the same magnitude.

New entry of sample persons is largely confined to individuals who were not eligible for interview in the first wave because aged less than 16, and may therefore be considered as exogenous. Different is the case of nonsample persons who joined the household of an original sample member after the first wave. Because their entry is often related to events, such as marriage, living arrangements, etc., that are at the same time the object of study using panel data, ignoring new entry may lead to a bias.

\section{Weighting}

To compensate for unequal selection probabilities and response rates, most public-use surveys assign weights to the response cases (households and persons). Under certain conditions, weighting the data helps obtain approximately unbiased estimates of population means and totals (see e.g. Little \& Rubin 1987, and Särndal, Swensson \& Wretman 1992). Although this is a standard practice, it is not without problems.

First, as pointed out by DuMouchel and Duncan (1983), while weighting may be appropriate for estimating population means and totals, relying only on weighted estimates may be dangerous in regression problems. Second, as stressed by Hoem (1989), weighting "can be superfluous in situations where the investigator is really involved in modeling human behavior rather than in calculating descriptive statistics for the finite population and ... may divert attention away from more important concerns of modeling and analysis". Third, as pointed out by Horowitz and Manski (1998), the use of general purpose (as opposed to model-based) weights may actually lead to estimates of regression relationships that lie outside the set of logically possible values.

The ECHP provides three types of cross-sectional weights: base weights, personal weights and household weights. Base weights are defined at the in- 
dividual level and represent the basis for constructing all the other weights and for adjusting weights from one wave to the next. Nonsample persons always receive a base weight of zero. Personal weights, instead, are nonzero for both sample and nonsample persons. Personal and household weights are intended to make the ECHP cross-sectionally representative for analyses at the individual and household level respectively. The remainder of this section briefly describes how the various weights are constructed.

\subsection{First wave}

Initially, in wave 1, the three types of weights coincide: there is no distinction between sample and nonsample persons and all members of an interviewed household receive the same weight, which is simply proportional to the household weight. These weights are computed through a sequential procedure consisting of the following steps:

1. Compute design weights $\omega^{(1)}$ inversely proportional to the household selection probabilities. If households are selected with uniform probabilities, then $\omega^{(1)}=1$.

2. Compute nonresponse weights $\omega^{(2)}$ inversely proportional to the response rates of each category or "weighting class" in which the sample has been partitioned. This step relies crucially on the assumption that, within each class, the nonrespondents are a random subsample of the sampled units. Construction of the weighting classes is based on variables available for both responding and nonresponding households, such as geographical location, tenure, and household size or type.

3. Compute weights $\omega^{(3)}$ correcting the distribution of households. These weights make the distribution of the households by various socio-economic characteristics agree with the corresponding distribution derived from the Census or the Labor Force Survey.

4. Compute weights $\omega^{(4)}$ correcting the distribution of persons. These weights make the distribution of the persons by sex and age agree with the corresponding distribution derived from the Census or the Labor Force Survey.

5. Compute the final weights as the product $\omega=\prod_{h=1}^{4} \omega^{(h)}$.

Steps 1 and 2 have been carried out by the NDUs, the other (mainly) by Eurostat. The weights obtained at each step have been trimmed in order to avoid extreme values and rescaled to average to one. Basic weights and personal weights are rescaled to average to one per person enumerated in the Register file, whereas household weights are rescaled to average to one per interviewed household.

Even after weighting, some discrepancies remain between the population distribution of households and persons and their distribution in the ECHP. For example, Table 13 shows that, at least in the case of Denmark (the only country for which detailed comparisons are currently available), the ECHP weights seem to overrepresent households consisting of a single person aged 60 or more, and households with no economically active persons. Given the role of the ECHP in social policy design, the consequences of these discrepancies are potentially worrysome. 
Table 13. Weighting of wave 1 for Denmark. Source: Eurostat (1995)

\begin{tabular}{|l|c|r|}
\hline & Population \% & ECHP \% \\
\hline Household type: & & \\
- Single male aged 60+ & 4.7 & 5.7 \\
- Single female aged 60+ & 12.6 & 13.5 \\
- Single male under 60 & 15.8 & 15.3 \\
- Single female under 60 & 10.2 & 9.5 \\
- Couple with no children & 25.5 & 26.0 \\
- Couple with children all less than 16 & 13.9 & 13.5 \\
- Couple with some children aged 16+ & 10.9 & 10.3 \\
- Other & 6.4 & 6.2 \\
\hline Total & 100.0 & 100.0 \\
\hline Number of economically active persons: & & \\
- No person & 26.3 & 28.4 \\
- One person & 35.7 & 35.2 \\
- Two or more persons & 38.0 & 36.4 \\
\hline Total & 100.0 & 100.0 \\
\hline
\end{tabular}

\subsection{Subsequent waves}

The base weights of sample persons are computed recursively from the ones of the previous wave, whereas the base weights of nonsample persons are always equal to zero. More precisely, the base weight $\omega_{i h}(t)$ assigned to sample person $i$ in household $h$ interviewed both in wave $t-1 \geq 1$ and wave $t$ is equal to

$$
\omega_{i h}(t)=f_{i h}(t) \omega_{i h}(t-1),
$$

where $f_{\text {ih }}(t)$ is an adjustment factor and $\omega_{\text {ih }}(t-1)$ is the weight assigned in wave $t-1$. Children born to a sample woman receive the same base weight as the mother. Notice that, unlike wave 1, basic weights of sample persons need not be the same within a household.

The base weights assigned to sample persons represent the basis for deriving all the other weights. The weight assigned to a household is proportional to the average value of the base weights of its members (either sample or nonsample persons). These household weights are scaled to average to one per interviewed household. Finally, to allow for cross-sectional representation of the population, all members of a household, whether sample or nonsample persons, receive a positive weight that is proportional to the household weight. These cross-section personal weights are scaled to average to one per person enumerated in the Register file. Thus, household and personal weights are essentially the same and only differ in the overall scale.

The adjustment factors $f_{\text {ih }}(t)$ are computed taking into account both attrition and changes in the distribution of the population. More precisely, adjustment factors are initially computed as

$$
f_{i h}(t)=\frac{1}{c_{i h}(t) r_{i h}(t)},
$$


Table 14. Results of an OLS regression of $\ln \left[\omega_{i h}(t) / \omega_{i h}(t-1)\right]$ on a constant and the logarithm of the retention probability estimated from the logit models in Section 4.3

\begin{tabular}{|c|c|c|c|c|}
\hline & \multicolumn{2}{|c|}{ Waves 1 to 2} & \multicolumn{2}{|c|}{ Waves 2 to 3} \\
\hline & Slope & $R^{2}$ & Slope & $R^{2}$ \\
\hline Belgium & $1.340^{* *}$ & .006 & $-1.195^{* *}$ & .023 \\
\hline Denmark & $1.205^{* *}$ & .028 & $.235^{* *}$ & .001 \\
\hline France & $.995^{* *}$ & .038 & $.671^{* *}$ & .009 \\
\hline Germany & $.271 * *$ & .002 & $-.311^{* *}$ & .004 \\
\hline Greece & $.291 * *$ & .001 & $-2.565^{* *}$ & .072 \\
\hline Ireland & $.439 * *$ & .011 & $-.771 * *$ & .042 \\
\hline Italy & $4.265^{* *}$ & .013 & $-12.950 * *$ & .006 \\
\hline Luxembourg & .080 & .000 & $-2.366^{* *}$ & .046 \\
\hline Netherlands & $.643^{* *}$ & .004 & $.821 * *$ & .019 \\
\hline Portugal & $.838 * *$ & .003 & $-.340^{* *}$ & .001 \\
\hline Spain & $.792 * *$ & .004 & .020 & .000 \\
\hline UK & $.246^{* *}$ & .002 & $-.853^{* *}$ & .023 \\
\hline
\end{tabular}

where $c_{i h}(t)$ is an estimate of the probability that a sample person from wave $t-1$ is successfully contacted in wave $t$, and $r_{i h}(t)$ is an estimate of the probability that a contacted person is successfully interviewed. These contact and interview rates are estimated by probit or logit under the implicit assumption that attrition is random after conditioning on the selected covariates. The results are then modified to correct for the distribution of persons by sociodemographic characteristics (sex, age group, region of residence) and household characteristics (household size and number of working persons in the household). Finally, adjustment factors are trimmed to avoid extreme values and rescaled in such a way that the base weights average to one for interviewed persons (sample and nonsample).

If we neglect the adjustment to external control distributions, trimming and rescaling, then the ratio $\omega_{i h}(t) / \omega_{i h}(t-1)$ of the base weights in two adjacent waves is inversely proportional to the longitudinal retention probability. Therefore, an OLS regression of the logarithm of the ratio on a constant and the logarithm of the retention probability (estimated from the logit model of attrition in Section 4.3) ought to have a slope approximately equal to minus one. Table 14 presents, for each country, the results obtained from this type of regressions. Quite surprisingly, the regressions explain very little of the changes in the base weights across waves and their slopes are generally far from minus one. Altogether, these results cast serious doubts on the nature of the weights provided by Eurostat. ${ }^{12}$

\section{Imputation}

Imputation consists of filling-in values that are missing because of item nonresponse. Imputing missing values is sometimes advocated on the ground that

\footnotetext{
${ }^{12}$ In August 2000, Eurostat announced a thorough revision of the weights in the next release of the UDB.
} 
Table 15. Imputation by income component. Column A shows the average proportion of income in a component which has been imputed, whereas column B shows the average proportion of income which has been imputed among the households receiving positive amounts of that component

\begin{tabular}{|l|ll|ll|lr|}
\hline & \multicolumn{2}{|c|}{ Wave 1 } & \multicolumn{2}{c|}{ Wave 2 } & \multicolumn{2}{c|}{ Wave 3 } \\
\cline { 2 - 8 } & $\mathrm{A}$ & $\mathrm{B}$ & $\mathrm{A}$ & $\mathrm{B}$ & $\mathrm{A}$ & $\mathrm{B}$ \\
\hline Total net household income & .107 & .107 & .111 & .111 & .109 & .109 \\
\hline Net income from work & & & & & & \\
- Wage and salary earnings & .033 & .050 & .044 & .066 & .026 & .042 \\
- Self-employment earnings & .089 & .534 & .093 & .530 & .099 & .551 \\
\hline Non-work private income & & & & & & \\
- Capital income & .163 & .569 & .232 & .629 & .189 & .547 \\
- Property/rental income & .001 & .023 & .002 & .033 & .002 & .026 \\
- Private transfers received & .008 & .128 & .008 & .116 & .077 & 1.000 \\
\hline Social insurance receipts & & & & & & \\
- Unemployment benefits & .007 & .069 & .005 & .050 & .005 & .044 \\
- Old age/survivors' benefits & .020 & .064 & .017 & .051 & .013 & .041 \\
- Family related allowances & .009 & .044 & .007 & .031 & .007 & .029 \\
- Sickness/invalidity benefits & .007 & .056 & .008 & .069 & .007 & .055 \\
- Education-related allowances & .003 & .124 & .004 & .105 & .004 & .105 \\
- Any other personal benefits & .002 & .052 & .002 & .056 & .003 & .089 \\
- Social assistance & .000 & .011 & .000 & .004 & .000 & .004 \\
- Housing allowance & .001 & .012 & .001 & .013 & .001 & .013 \\
\hline Monthly wages (current) & .047 & .081 & .036 & .057 & .007 & .011 \\
\hline
\end{tabular}

it makes the data easier to analyze - for standard methods (e.g. least-squares) may then be applied to the completed data - and reduces nonresponse bias relative to the alternative of excluding all observations with missing values.

As pointed out by Dempster and Rubin (1983), however, "the idea of imputation is both seductive and dangerous. It is seductive because it can lull the user into the pleasurable state if believing that the data are complete after all, and is dangerous because it lumps together situations where the problem is sufficiently minor that it can legitimately be handled in this way and situations where standard estimators applied to real and imputed data have substantial bias". Further, imputation is time-consuming and, if carried out by the data collecting agency, it may lead to unnecessary delays in the release of the data, as is indeed happening with the ECHP.

\subsection{Items imputed}

So far, primary objective of the ECHP team has been to imputed values for total net household income and a number of intermediate components of household income listed in Table 15. For each imputed income component, an "imputation index" is provided that is equal to the proportion of reported income which arises from imputation. Table 15 shows, for each income component, the average proportion of income which has been imputed (column A), along with the average proportion of income which has been imputed 
among the households receiving positive amounts of that component (column B). ${ }^{13}$ The table confirms the importance of item nonresponse and imputation for household income.

Turning to individual income, it is unclear the extent of imputation in this case. According to Eurostat (1999): "some 'preliminary' imputations may be involved at the level of detailed components [...]. These include:

- imputation of an actual amount when only a range has been specified

- imputation of the months received where only the average amount per month has been specified,

- estimation of the net when only a gross amount has been given,

- whether a particular component that is received is not-stated."

Unfortunately, no flag is provided by the UDB in these cases. Further, it is not clear whether a zero value for a particular income component corresponds to non recipiency or rather to a missing value.

\subsection{Imputation methods}

The main imputation method for wave 1 data has been random hotdeck within classes. ${ }^{14}$ To impute the missing value of a target variable $Y$ for the $i$ th sample unit, this method first partitions the sample into a number of "imputation classes" defined on the basis of a set of variables which includes socio-demographic characteristics (sex, age, schooling, employment status) and characteristics of the job held (present occupation, main activity, hours worked per week). A "donor" $j$ is then selected at random from the subsample of the respondents within the class containing the $i$ th sample unit, and the imputed value of $Y_{i}$ is computed as $Y_{i}^{*}=Y_{j}$. The imputed value $Y_{i}^{*}$ is therefore a random draw from the empirical distribution of the observed values of $Y$ within the class. This method guarantees that imputed values are always plausible and, unlike deterministic imputation methods, avoids understimation of the variability of $Y$. In order to preserve key covariances, the same donor has been used for imputation of related missing variables.

For reasons which are not clear, starting with wave 2 Eurostat switched to a different imputation method. From the limited information available (Eurostat 1997a, 1999), the new method consists of a sequential procedure where the imputed values of a target variable are computed by stochastic regression imputation based on auxiliary variables, some of which have themselves been imputed at earlier stages of the process. ${ }^{15}$ Stochastic regression imputation adds to the predicted value of the target variable a stochastic component which is randomly drawn from the empirical distribution of the regression residuals. The order with which the target variables enter the sequence depends on the amount of missing data. Variables with a small fraction of

13 Thus, the ratio of column A to column B gives the fraction of households with non missing income component which receive positive amounts of that income component.

${ }^{14}$ According to Eurostat (1997a), "minor components of income and some household income were imputed using ad hoc methods developed ... by Eurostat".

${ }^{15}$ Wave 1 values, whether imputed or not, may also be employed as auxiliary variables. 
missing data are imputed first and may then be used as auxiliary variables to construct imputations for variables with a higher fraction of missing data.

A key ingredient of both methods is the assumption that data are missing at random conditional on the covariates that define the imputation classes or are employed as auxiliary variables. This assumption is untestable unless external information is available, such as administrative records or a follow up of nonrespondents. If this assumption does not hold, which is likely to be the case with at least some of the income components, then other imputation methods should be considered that explicitly model the nonresponse mechanism (see e.g. Greenlees, Reece \& Zieschang 1982). To my knowledge, these methods have not been tried in the ECHP.

The problem of inference in the presence of imputed values is also important, as the use of complete-data methods will overestimate precision, but has not been addressed by Eurostat. Two alternatives may be considered. One is the multiple imputation approach proposed by Rubin (1987), the other is the use of bootstrap methods (Efron 1994). In multiple imputation, each missing value is replaced by a vector of $m \geq 2$ imputed values, thus giving $m$ completed data sets which can be analyzed using standard complete-data methods. The variability of the resulting estimates provides a measure of the uncertainty due to the presence of missing values.

In his comment to Efron's paper, Rubin argues that "multiple imputation is designed to be particularly appropriate for shared (i.e. public-use) data bases, collected and imputed by one entity but analyzed by a variety of users typically armed with only standard complete-data software", whereas bootstrap methods "are more oriented towards situations where the imputer and the data analyst are the same entity and, moreover, an entity with access to substantial computing power".

\section{Conclusions}

So far, the analysis of a large set of issues (labor force participation decisions, human capital investment decisions, retirement decisions, earnings structure and dynamics, effects of training programs, effects of social protection programs, etc.) has been made substantially more difficult in Europe than in the USA by the lack of adequate information, especially longitudinal data.

From this viewpoint, Eurostat's decision to launch the ECHP is to be praised, as it represents an important step forward in filling the informational gap between Europe and the USA. Unfortunately, the hopes of a quick release of these data have been frustrated, and public-use files have been made available only very recently. Further, access to these data is far from easy, due to both the high price and the strict contractual conditions. This situation has obvious negative consequences, not just for the potential users, but for Eurostat itself that is deprived of important feedback which may help improve data quality.

Appreciation, by the academic community and the public at large, of the effort carried out by Eurostat with the ECHP survey can only come if the data are made more widely available to researchers, and the associated methodological and statistical issues (nonresponse, attrition, weighting, imputation, etc.) are openly discussed and well understood. 


\section{References}

Becketti S, Gould W, Lillard L, Welch F (1988) The panel study of income dynamics after fourteen years: An evaluation. Journal of Labor Economics 6:472-492

Dempster AP, Rubin DB (1983) Overview. In: Madow WG, Olkin I, Rubin DB (eds) Incomplete Data in Sample Surveys, Vol. II, Academic Press, New York

DuMouchel WH, Duncan GJ (1983) Using sample survey weights in multiple regression analysis of stratified samples. Journal of the American Statistical Association 78:535-543

Duncan GJ, Hill DH (1989) Assessing the quality of household panel data: The case of the panel study of income dynamics. Journal of Business and Economic Statistics 7:441-452

Efron B (1994) Missing data, imputation, and the bootstrap (with discussion). Journal of the American Statistical Association 89:463-479

Eurostat (1995) Weighting results of wave 1: empirical results. PAN 46/95, Eurostat, Luxembourg

Eurostat (1996a) European Community Household Panel (ECHP): Methods. Survey questionnaires: Waves 1-3. Office for Official Publications of the European Communities, Luxembourg

Eurostat (1996b) The European Community Household Panel (ECHP): Survey methodology and implementation. Volume 1, Office for Official Publications of the European Communities, Luxembourg

Eurostat (1997a) Longitudinal imputation. PAN 88/97, Eurostat, Luxembourg

Eurostat (1997b) Response rates for the first three waves of the ECHP. PAN 92/97, Eurostat, Luxembourg

Eurostat (1999) ECHP UDB manual. Waves 1, 2 and 3, mimeo, Eurostat, Luxembourg

Eurostat (2000) ECHP data quality. PAN 108/99 Revised, Eurostat, Luxembourg

Fitzgerald J, Gottschalk P, Moffitt R (1997) An analysis of sample attrition in the michigan panel study of income dynamics. mimeo

Greenlees JS, Reece WS, Zieschang KD (1982) Imputation of missing values when the probability of response depends on the variable being imputed. Journal of the American Statistical Association 77:251-261

Hill MS (1992) The panel study of income dynamics. A user's guide. Sage Publications, Newbury Park, CA

Hoem JM (1989) The issue of weights in panel surveys of individual behavior. In: Kasprzyk D, Duncan GJ, Kalton G, Singh MP (eds) Panel Surveys. Wiley, New York

Horowitz J, Manski CF (1998) Censoring of outcomes and regressors due to survey nonresponse: Identification and estimation using weights and imputations. Journal of Econometrics 84:37-58

Lillard L (1989) Sample dynamics: Some behavioral issues. In: Kasprzyk D, Duncan GJ, Kalton G, Singh MP (eds) Panel Surveys. Wiley, New York

Little RJA (1982) Models for nonresponse in sample surveys. Journal of the American Statistical Association 77:237-250

Little RJA, Rubin DB (1987) Statistical analysis with missing data. Wiley, New York

O’Muircheartaigh C (1989) Sources of nonsampling error: Discussion. In: Kasprzyk D, Duncan GJ, Kalton G, Singh MP (eds) Panel Surveys. Wiley, New York

Peracchi F, Welch F (1995) How representative are matched cross-sections? Evidence from the current population survey. Journal of Econometrics 68:153-180

Rubin DB (1987) Multiple imputation for nonresponse in surveys. Wiley, New York

Särndal C-E, Swensson B, Wretman J (1992) Model assisted survey sampling. Springer, New York

Schaber G, Schmaus G, Wagner G (1993) The PACO project. PACO Research Paper \#1, CEPS/ INSTEAD, Luxembourg

Verma V (1995) Item non-response and frequency distributions: Household questionnaire wave 1. Illustration from two countries (DK, UK). PAN 60/95, Eurostat, Luxembourg 